José Florencio F. Lapeña, Jr., MA, MD

Department of Otorhinolaryngology College of Medicine, University of the Philippines Manila, Philippines

Department of Otorhinolaryngology Head and Neck Surgery

East Avenue Medical Center, Diliman Quezon City, Philippines
Correspondence: Prof. Dr. José Florencio F. Lapeña, Jr. Department of Otorhinolaryngology Ward 10, Philippine General Hospital University of the Philippines Manila

Taft Ave., Ermita, Manila 1000

Philippines

Phone: (632) 5264360

Telefax: (632) 5244455

Email: lapenajf@upm.edu.ph

Reprints will not be available from the author.

The author declared that this represents original material that is not being considered for publication or has not been published or accepted for publication elsewhere, in full or in part, in print or electronic media; that the manuscript has been read and approved by the author, that the requirements for authorship have been met by the author, and that the author believes that the manuscript represents honest work.

Disclosures: The author signed a disclosure that there are no financial or other (including personal) relationships, intellectual passion, political or religious beliefs, and institutional affiliations that might lead to a conflict of interest.

\section{On Research and Publication: The Specialty Society and its Scholarly Journal}

\author{
"Research, no matter how'good', is incomplete, until it has been published."1
}

The Philippine Society of Otolaryngology Head and Neck Surgery has been promoting research among Residents and Fellows through various fora (including research contests), even creating a research fund (albeit, with no takers). It has also supported the Philippine Journal of Otolaryngology Head and Neck Surgery as its official scientific publication and primary forum for publishing research. This year, our Board of Trustees has finally taken concrete steps to merge our research and publication initiatives in order to streamline both processes. In effect, all papers submitted to the various research contests of the society will be reviewed and revised prior to oral presentation, through the editorial management system of our journal. In this manner, both the contests and the journal benefit, as pre-final papers chosen for oral presentation would have already been reviewed and revised for publication. Indeed, "publishing" means to make something public. If the ratio of research presentations to publications is taken, it is fair to conclude that we may not lack in research, but we certainly lag in publication. Why publish?

"Similar to others who write (historians and poets), scientists and those involved in research need to write ... to leave behind a documented legacy of their accomplishments."' Whatever we discover or unearth in the laboratory, clinic or in the field; whether from samples, specimens, subjects, patients or participants; utilizing theoretical or applied instruments, materials and methods; simply "did not happen" unless it is documented and disseminated. In Filipino,"kung hindi nakasulat, hindi nangyari." How often do we hear side-comments like "naisip ko na iyan," or "na-presenta ko na iyan" or even "sinulat ko na iyan" at a scientific meeting where a speaker presents a study. The sad fact of the matter is many of these colleagues may indeed have had similar thoughts, or delivered previous oral presentations, or even written reports. But because not of these had been properly published, they remain inaccessible to subsequent scholars, and are therefore neither cited nor acknowledged.

"While 'doing' the research is important, 'writing' about why and how it was done, what was found, and what it means is far more important as it serves as a permanent record of scientific work that has been completed and accepted by peers."1 And writing and publishing are an entirely different ball game from researching alone. Publication, or "making ideas public," allows 
"scholars (to) provide each other with the opportunity to build on each other's contributions, create dialogue (sometimes heated) with one another and join the documented and ongoing history of their field."2 It is by participating in this "documented and ongoing history" of our field that we and our specialty society gain international recognition and become internationally competitive.

Taking your place in the history of scholarship starts where you are, as an author. Publication involves communication between the author and his or her audience via the written article. ${ }^{3}$ Unlike public speakers or performing artists, the author's interaction with the audience is limited by the written and published work. Hence, "a successful researcher is usually a good communicator who has the ability to maximize the transmission of research findings to his or her chosen audience." Our journal editors "go the extra mile" to maximize manuscripts for communication. Unlike most journals, we do not reject poorly-written submissions outright and often help rewrite them extensively. Aside from form- and content- editing, we even assist in revisions following the review process. Unfortunately, few authors seem to appreciate or understand this-and ironically, those who do are mostly overseas authors. Perhaps our local colleagues do not fully realize the career, professional, institutional and practical advantages that can be gained from writing and publication. ${ }^{4}$

Career benefits of publication "may have the most direct bearing on ... appointment, promotion, tenure and advancement within your institution, organization and discipline."2 This is especially true for those of us in academe, but it certainly should also be true as far as our specialty training and accreditation programs are concerned. For instance, publications of specialty board examiners and accreditors are integral to their appointment and retention in learned societies here and abroad.

Professional benefits include "applying for positions in foreign institutions, and when applying for competitive overseas fellowships" ${ }^{\prime \prime}$ I have received numerous urgent requests from residents and young diplomates (unaware of the editing and peer review process) to publish research they undertook in training so they can fulfill publication requirements for overseas positions or fellowships. For more senior consultants, "gaining recognition as experts ... at regional and international levels leads to invitations to lecture at scientific meetings ... appointments as consultants to external agencies ... and advisory boards." Closer to home, publication "increases depth of knowledge in a particular subject that complements and hones clinical skills, and enables better teaching of students, clinical trainees and postgraduates."1

Concerning institutional benefits, "publication in peer-reviewed journals is arguably the most important means to achieve international recognition for an individual, department, hospital, and university."1 Moreover, "the author's country, and even the region, may also derive benefit from published work, particularly if it is on a topic of major importance."1 At least in the medical field, Filipino publications have made their mark, although sparsely.

Finally, the practical benefits gained from engaging in the research and publication process cannot be overlooked. The "inherent training gained during the process of manuscript preparation," the "discipline of performing a thorough literature search, collating and analyzing data and drafting and repeatedly revising the manuscript"1 during the editing and review process, provide undeniable practical benefits to the author. Researchers who have published are much better positioned to evaluate scholarly publications, having themselves experienced the writing, editing and review process. In this era of "information overload" the published researcher can more effectively evaluate and utilize available evidence. This translates to elevating the scientific and scholarly milieu in our specialty society and training institutions.

Indeed, we are entering a new era for both the PSOHNS and PJOHNS. Hopefully, the streamlined submission and review process will facilitate presentation and publication, in quantity and quality for many years to come.

1. Peh WCG, Ng KH. Effective medical writing (Pointers to getting your article published): Why Write? Singapore Med J 2008; 49(6):443.

2. Publish, Not Perish: The Art and Craft of Publishing in Scholarly Journals. University of Colorado 2006. Available from http://www.publishnotperish.org [cited May 25, 2013].

3. Clearihan Lyn. Writing for Publication. Monash Uniiversity, Melbourne. Available from: http:// www.phcris.org.au/conference/2005/workshops/clearihan.pdf [cited May 25, 2013].

4. Peh WCG. Scientific writing and publishing: its importance to radiologists. Biomed Imaging Interv J 2007;3(3):e55 doi: 10.2349/biij.3.3.e55
} 